\title{
Structural Color for Wood Coloring: A Review
}

\begin{abstract}
Jing $\mathrm{Hu},{ }^{\mathrm{a}, \mathrm{b}} \mathrm{Yi} \mathrm{Liu},{ }^{\mathrm{a}, \mathrm{b}, *}$ and Zhihui $\mathrm{Wu}{ }^{\mathrm{a}, \mathrm{b}, *}$
The color, texture, and natural defects of wood are important factors affecting its commercial value. Change of wood's surface color is a primary way to improve its value. This study analyzes and summarizes the development status and existing problems of the traditional wood dyeing process and induced discoloration process. It is proposed that color improvement with photonic crystal structure color is a clean and pollutionfree ecological biomimetic coloring technology. Its research status in the fields of fiber, fabric, wood, wood-based panel surface color improvement, new coatings for wood, and lignocellulose nanocrystalline structure color film are reviewed. The following aspects were studied: 1) construction and mechanistic study of the wood surface structure color film, 2) light response and interface mechanistic study of the wood surface structure color film, 3) large-scale application technology study of the wood surface biomimetic structure color film, and 4) preparation and functional development of structural color films of lignocellulose nanocrystal.
\end{abstract}

Keywords: Wood; Biomimetic; Photonic crystal; Structure color; Lignocellulose nanocrystal

Contact information: a: College of Furnishings and Industrial Design, Nanjing Forestry University, No. 159 Longpan Road, Nanjing 210037, China; b: Jiangsu Co-Innovation Center of Efficient Processing and Utilization of Forest Resources, No. 159 Longpan Road, Nanjing 210037, China;

*Corresponding authors: liuyi@njfu.edu.cn; wzh550@njfu.edu.cn

\section{INTRODUCTION}

\section{Wood Color Improvement Technology and Existing Problems}

As one of the materials with the closest relationship with humans, and the most harmonious development with the environment, wood is widely used in the buildings and furniture of the human living environment, due to its good environmental characteristics and excellent thermoelectric insulation (Kanaya et al. 2016; Strobel et al. 2017). Compared with other commonly used building materials, such as steel and concrete, wood has the advantages of low density, high strength-to-weight ratio, easy processing, beautiful texture, rich color, good elasticity, and it is a renewable natural resource (Knudson and Brunette 2015; Borrega et al. 2015; Bao et al. 2016; Wang et al. 2016; Gamaliel et al. 2018; Liu et al. 2019; Yang et al. 2019). One of the important factors affecting the commercial value of wood is its material color and texture. The natural appearance defects of wood, such as large irregular color difference and monotonous color, can be eliminated by bleaching, dyeing, and surface finishing, which improve wood's visual characteristics and decorative properties. At the same time, the value of low-quality wood can be improved by imitating the color of wood from highly valued trees.

\section{Traditional Wood Dyeing Process and Existing Problems}

Dyeing is an important step from an industrial perspective. The desired color of wood is achieved by using chemical colorants. To change the color of wood or simulate the texture of wood, the usual method is to use chemical dyes to react with wood, i.e., the 
wood dyeing process. However, the dyes used have some problems, such as poor light resistance, low color fastness, chemical stability, and some dyes contain toxic heavy metal components, such as lead and chromium. Additionally, in the traditional wood dyeing process, water consumption is large, and the dye loss rate is much higher than that in textile dyeing process (Vakhittova and Safonov 2003). More importantly, various auxiliaries (osmotic agents, dyeing aids, etc.) added during dyeing are passed forward, in large quantities, to the wastewater (Gogate and Pandit 2004; Kušić et al. 2007). Most of these dyes and auxiliaries are synthesized artificially and have poor biodegradability. Such a process will not only lead to a waste of resources, but also they will contribute to high chroma, high content of organic and inorganic salts, high chemical oxygen demand (COD), and low biochemical oxygen demand (BOD) in wastewater. The biodegradability index (BOD/COD) decreased, which due to the application of complexity and variability organics that are difficult to biodegrade (You et al. 2018). This phenomenon will lead to poor water quality and long-term harm to the natural environment.

Wood has a natural porous structure. Dye molecules enter the wood through the multilevel infiltration channels of wood cells, adsorbing, settling, and fixing on the cell surface to achieve the purpose of dyeing (Hu et al.2016). Among the common dyes, acid, basic, and direct dyes combine with wood components through intermolecular forces and hydrogen bonding, resulting in poor color fastness (Ghafarzadeh et al. 2018). Reactive dyes can be covalently linked with wood components through active groups, resulting in excellent dye uptake and color fastness (Schmidt et al. 2003; Wang et al. 2018; Jaxel et al. 2020). However, chemical groups that modify the hue of a colorant, such as hydroxyl or amino substituent group associated with aromatic rings, in the dye molecular structure are easily oxidized by light to produce free radicals and light aging (Yang et al. 2020). Using textile dyeing technology for reference, natural plant dyes are used in wood dyeing research, but their color fastness is poor (Zhu et al. 2018).

To improve the light resistance of dyed wood, a series of studies have been conducted. It was found that the light resistance of dyed wood is related to the structure and composition of substrate, the type and structure of dyes, the combination mode of dyes and wood, and the wavelength and temperature of light radiation (Liu et al. 2015). To solve the problem of light fastness of dyed wood, acetylation, benzoylation, chitosan solution treatment of wood, ultraviolet light absorbers, such as benzotriazole and benzophenone, and light stabilizers, such as steric amine and polyethylene glycol (PEG) 4000, can effectively prevent and control the photochromism of dyed wood (Mamnickal and Czajkowski 2012; Rajan et al. 2012; Xiao et al. 2012; Choi and Chung 2013; Liu et al. 2013; Li et al. 2015). The free amino group in chitosan can accept positively charged hydrogen ions under acidic conditions, reducing the repulsion between anions and dyes on the surface of the wood fiber and improve the dye uptake. At the same time, the $\mathrm{NH}_{2}$ groups in the chitosan molecule can react with the sulfonic group in the dye under acidic conditions to form sulfonate, which helps in color fixation (Wang et al. 2016). Like the chitosan solution, many amino groups are present in water-soluble organic resin, such as melamine urea formaldehyde resin, which can improve the dyeing effect and color fastness of dyes (Hansmann et al. 2006; Deka et al. 2007).

\section{Techniques of Wood Induced Discoloration and Existing Problems}

In addition to dyeing the wood to change its color, other methods have been explored to improve the functionality of wood's color. Fungal infection can discolor the wood and form mycorrhizal wood. A series of studies have been conducted on wood fungus 
dyeing methods, dyeing conditions, wood properties, and mechanisms (Robinson et al. 2007, 2014; Gutierrez and Robinson 2017; Hinsch and Robinson 2018; Liu et al. 2020b). However, limited by the randomness of fungal growth footprints and uniform staining, directional regulation of decorative texture cannot be achieved presently. With the development of microbial technology, it is necessary to further explore whether it can induce microorganisms to regulate the decorative texture of the wood surface, and whether it can regulate the growth footprint of microorganisms to dye the wood evenly.

Wood heat treatment technology can effectively improve the dimensional stability of wood. After heat treatment, the wood color is deepened, and the brightness is reduced. The color of ash, Douglas fir, and other wood materials (Bekhta and Niemz 2003; Sundqvist et al. 2006; Esteves et al. 2008; Cakicier et al. 2011; Li et al. 2011; Salca et al. 2016) can be adjusted closely to the color of a selected high-valued wood, and the original appearance defects of the wood can be covered simultaneously. However, during use, under the influence of temperature, humidity, light, rain, and other factors, the lignin content will gradually decrease, holocellulose will become the main component of cell wall, and the surface wood color will gradually turn gray (Huang et al. 2012).

Temperature-sensitive toners are used in wood surface finishes. After heating up or cooling down to the response temperature of the toner, the color of the coated material will be converted to a colorless form, or a polychromatic phenomenon will be observed. During fading, the wood color gradually becomes like that of wood without adding toner. When transparent varnish was applied, the discoloration would exhibit a hysteresis phenomenon (Zhu et al. 2017, 2018). Through building a $\mathrm{WO}_{3}$ nanometer modification layer on the wood surface, wood can achieve reverse photochromic ability. After modification, the brightness of the wood color decreases. When excited by UV light, the color of modified wood changes from warm to cold (meaning generally changing from yellowish in the direction of greenish), the $b^{*}$ values showed great variation, with $a^{*}$ constant in the Commission Internationale de L'Eclairage (CIE) Lab coordinates (Sun and Song 2018).

In view of the traditional wood dyeing technology, although the light fastness can be improved by using dyes, wood treatment, adding light absorbents, and other methods, the environmental pollution has not been solved. However, there are some problems, such as uncontrollable processes and effects, poor weather resistance, and limited application range in the new technology of wood color improvement, as well as induced discoloration. According to the principle of color production, learning from nature and introducing structural color into the field of wood color improvement can fundamentally solve the problems of color fading and environmental protection of dyed wood.

\section{BIOMIMETIC STRUCTURE COLOR}

\section{Natural Biological Structure Coloring}

Light is an electromagnetic wave with a single or mixed frequency, and it has no color of its own. Color is the reflection of human visual system to visible light. The color of visible light is an electrical signal produced by chemical changes in the photoreceptors in the retina caused by light entering the eye. The signal is transmitted from the optic nerve to the visual center of the brain, and the result is translated by the brain, i.e., the visible light of a certain frequency band produces certain color reflection (Nassau 2001).

In nature, animals and plants often use their own colors and patterns to achieve specific biological functions, such as concealment, interspecific recognition, intraspecific 
communication, attracting heterosexual partners (courtship), and repelling natural enemies. The color of an organism originates from its pigment color and/or structure color. The coloring mechanism of pigment color is related to electronic transition and molecular orbital theory, while structural color is the color produced by the diffraction or scattering of light caused by the microstructure of the surface of organism. If the microstructure and its components remain unchanged, structural color will never fade (Kinoshita and Yoshioka 2005; Takeoka 2012, 2013).

Structural color is a gift from nature. According to the interactions of visible light and microstructure, the structure color can be produced in the form of film interference, grating diffraction, and photonic crystals. Among them, the color generation of photonic crystal structures can be attributed to the band gap characteristics of the forbidden effect on specific frequency band light, conforming to the Bragg diffraction theorem (Born and Wolf 1999). In the visible spectrum, the photonic crystals that produce structural colors have a periodicity equal to half of the wavelength of light wave, which is about 170 to 370 $\mathrm{nm}$. Moreover, the reflected light will change with the angle of observation and exhibit an iridescence effect. In natural organisms, a three-dimensional (3D) photonic crystal structure composed of nanoparticles widely exists ( $\mathrm{Zi}$ et al. 2003; Galusha et al. 2008; Prum et al. 2009; Saranathan et al. 2010; Yin et al. 2012; Chen et al. 2015). As shown in Fig. 1 ( $a, b$, and c), photonic crystal structures arranged by microspheres of similar diameter exist in the chest and abdomen of Enallagma civile, and in the corolla of Lepidothrix coronata, and Cystoseira tamariscifolia, presenting bright structural color (Prum et al. 2004; Forster et al. 2010; Lopez-Garcia et al. 2018).

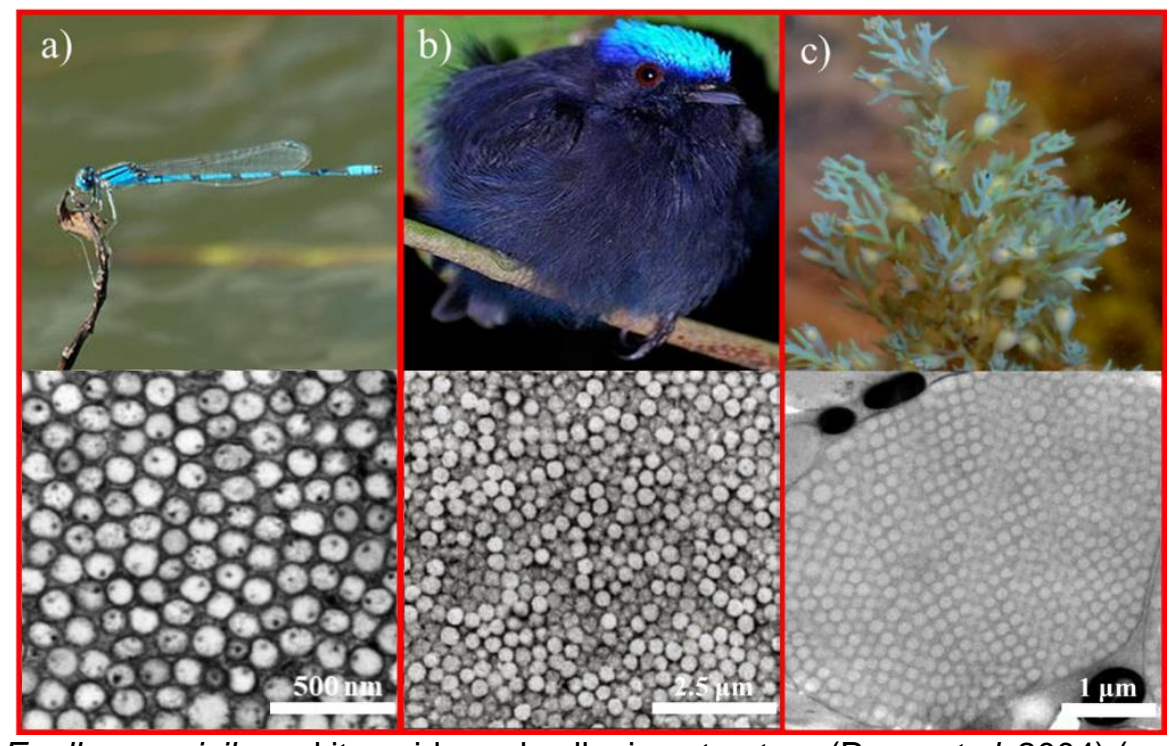

Fig. 1. (a) Enallagma civile and its epidermal cell microstructure (Prum et al. 2004) (reproduced with permission from the Company of Biologists Ltd.); (b) Lepidothrix coronata and its cut-in microstructure (Forster et al. 2010) (reproduced with permission from John Wiley and Sons); (c) Cystoseira tamariscifolia and its epidermal cells (Lopez-Garcia et al. 2018) (a derivative of "Lightinduced dynamic structural color by intracellular 3D photonic crystals in brown algae" by LopezGarcia et al. licensed under $\underline{\mathrm{CC} B Y}$ )

Inspired by the biomimetic nature, researchers began to artificially prepare photonic crystal structures, obtained different colors by adjusting their lattice parameters, and applied them to decoration, pigment, anticounterfeiting, sensing, switching, display, 
information storage, and other fields (Honda et al. 2009; Wang et al. 2012; Xuan and Ge 2012; Chen et al. 2013; Giese et al. 2014; Inan et al. 2017; Luo et al. 2017; Takeoka 2017; Isapour and Lattuada 2018; Wilts and Saranathan 2018).

\section{Biomimetic Photonic Crystal Self-assembly Preparation Technology}

Colloidal microspheres self-assemble to form photonic crystal structures with an ordered arrangement of high and low refractive index materials, which is effective in the generation of structural color (Mesnage et al. 2012). Compared to hole drilling, beam, micro processing, micro etching, and other photonic structure construction technologies, self-assembly technology of colloidal microspheres has become an important method for the preparation of photonic crystal structure due to its simple method, easy access to raw materials, and low cost. During self-assembly, to achieve the minimum free energy of the system, the colloidal microspheres automatically prepare a 3D ordered structure with highly ordered hexagonal close packing (HCP) or face centered cubic packing (FCC) (Pusey et al. 1989; Cheng et al. 1999; Wang et al. 2006; Míguez et al. 2007; Finlayson and Baumberg 2013), conforming to the Bragg diffraction theorem.

Gravity deposition (McGrath et al. 2007), vertical deposition (Jiang et al. 1999; Li and Marlow 2006), centrifugal method (Aguirre et al. 2010), pull-out method (Moon et al. 2005), and electrophoretic deposition (Trau et al. 1996; Rogach et al. 2000) are common ways to self-assemble colloidal microspheres to photonic crystals. The principle of these methods is to balance the attractive and repulsive forces to make the spheres self-assemble into photonic crystals. The colloidal crystal system becomes stable by utilizing entropy driving force, capillary force, electrostatic repulsion, and the gravity of the microspheres (Denkov et al. 1993; Visschers et al. 1997). There is no covalent bonding force between the microspheres. The stability of the colloid and the size and morphology of the microspheres significantly affects the optical properties of the assembled photonic crystals. The stability of the colloids can be improved by stereoscopic or electrostatic interactions in space. A colloidal system with good stability and high monodispersity can ensure thermodynamic stability during assembly (Schubert et al. 2007).

After hundreds of millions of years of natural selection and evolution, organisms have evolved a variety of microstructures, achieving the integration of structure and function. Bright structural colors are just one of them. By referring to the biological microstructure and combining the technology of artificial preparation of photonic crystals with wood, the dependence of wood color changes on pigment can be avoided and endow wood the ability to control light waves and structure coloring.

\section{APPLICATION OF BIOMIMETIC STRUCTURE COLOR IN MATERIAL COLOR IMPROVEMENT}

\section{Application in Textile Field}

Like wood dyeing, textile dyeing has the problem of severe environmental pollution caused by waste liquid, affecting the green development of the textile industry. Therefore, in the textile field, studies on structural color fiber and fabric have attracted wide attention (Liu et al. 2015; Liu et al. 2016; Gao et al. 2017). Photonic crystals have been constructed on the surface of cotton, silk, polyester, nylon, and other fabrics with different materials, colors, and textures. 
Kolle et al. (2013) coated polymers with different refractive indices to form a composite film and wrapped the film on the surface of a glass fiber with a diameter of 20 $\mu \mathrm{m}$, thus obtaining fibers with structural color. Use of hydrofluoric acid to remove glass fiber could form a hollow fiber with excellent tensile recovery performance. Through electrophoretic deposition, microspheres with different diameters could be assembled on carbon fiber and given different colors (Zhou et al. 2013). Monodisperse microspheres were mixed with binder and carbon black, such as polyacrylate (PA) and polyvinyl alcohol, and then sprayed and atomized on the surface of cotton and silk fabrics. The structural color patterns could be obtained through self-assembly (Zeng et al. 2017; Li et al. 2018). Yuan et al. (2017) used magnetron sputtering to prepare a nano $\mathrm{Ag} / \mathrm{TiO}_{2}$ composite film on polyester fabric to obtain textiles with structural color and achieve photoelectric functionalization. Liu et al. (2017) configured colloidal microsphere emulsions with different particle sizes into inks and achieved structural color printing of fabric by using inkjet. Park et al. (2015) prepared PS- $b-\mathrm{P}_{2}$ VP structural color films using an ionic liquid polymer and regulated the color of films by adjusting the voltage. The films could be directly transferred from one substrate to another.

\section{Application in the Wood Field}

In recent years, structural color has been applied to the wood field. Microspheres are used for the color improvement of wood surface, mainly polystyrene (PSt) (Zhang et al. 2003; Cong et al. 2013; Tang et al. 2014; Kohri et al. 2017) and silicon dioxide $\left(\mathrm{SiO}_{2}\right)$ (Wang et al. 2010; Zhao et al. 2011; Takeoka et al. 2013; Lei et al. 2014). PSt microspheres are prepared by emulsion polymerization. During synthesis, under the action of emulsifier and mechanical agitation, the monomer can form a stable emulsion in water or nonaqueous medium to achieve homogeneous or heterogeneous polymerization and form an emulsion polymer with colloidal solution characteristics. In contrast, $\mathrm{SiO}_{2}$ microspheres can be prepared using the Stöber method (Stöber et al. 1968). The reaction principle is that organic substances, such as ethyl orthosilicate (TEOS), are catalyzed by ammonia in an alcohol solution and form spheres after hydrolysis and condensation reactions.

In terms of wood surface color improvement, styrene was used as the main monomer to prepare monodisperse poly(styrene-methyl methacrylate-acrylic acid) (P(StMMA-AA)) core-structure colloidal microspheres through emulsion polymerization (Liu et al. 2020a). Photonic crystal films were fabricated on the surface of the wood using the static drop method. Through changing the diameter of the microspheres, the optical properties of films could be adjusted, and different colors could be obtained (Fig. 2).

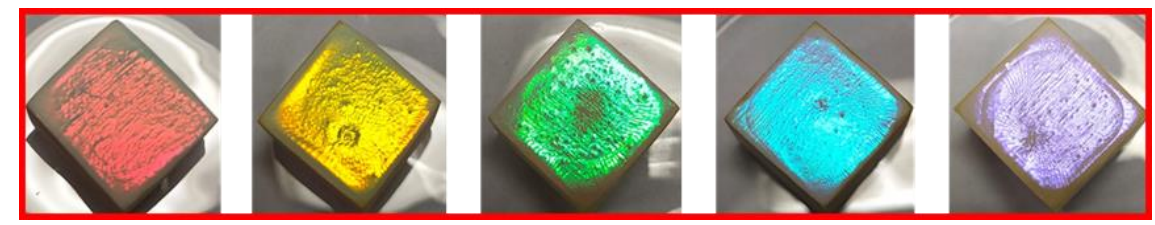

Fig. 2. Structure color film of $P$ (St-MMA-AA) colloidal microspheres on the wood surface

Shown in Fig. 3a is the transmission electron microscopy images of colloidal microspheres obtained by emulsion polymerization, where the dark part in the center of a single P(St-MMA-AA) microsphere is the PSt core and the light part at the edge is the P(MMA-AA) soft shell. Shown in Fig. 3b is the surface and cross-section scanning electron micrograph of the photonic crystal structures preliminarily prepared on the wood surface. 
The microspheres were arranged orderly on the wood surface to form the photonic crystal structure, in which there may be FCC or hexagonal close-packed structures. Although the photonic crystal structures of the film had some defects, it still showed the structural color. Shown in Fig. $3 \mathrm{c}$ is the change in film color due to different viewing angles, indicating that the film is like animal tissues and organs, and the structural color is angle dependent. In nature, animals can be courted or camouflaged with such structural color functions (Fig. $3 d)$.

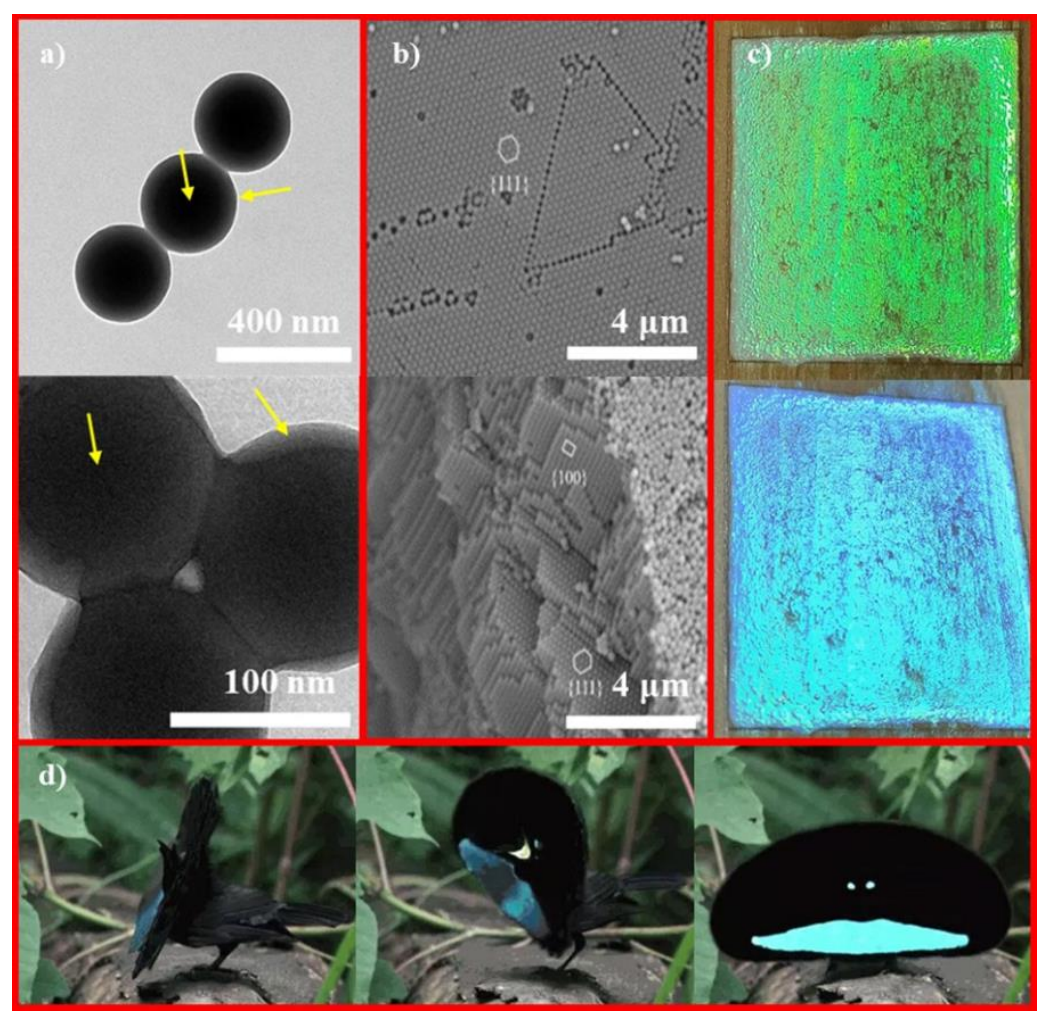

Fig. 3. (a) $P($ St-MMA-AA) core-shell structure of the colloidal microspheres; (b) Photonic crystal structures formed by self-assembly of P(St-MMA-AA) on the wood surface; (c) Angle dependence of the color of biomimetic structure film on the wood surface; (d) Lophorina superba unfurls a thoraco-shield feather with an angle-dependent structural color during courtship

According to the surface structure color decoration of different species of wood, Núñez-Montenegro et al. (2020) selected the wood of Handroanthus chrysotrichus, Dipteryx odorata, Hymenaea courbaril, Quercus robur, Pinus pinaster, and Bowdichia nitida with different colors. Through self-assembly with UV light as the heat source, both polymer colloidal microspheres and $\mathrm{SiO}_{2}$ microspheres constructed a structural color coating on the wood surface. However, the coating structure color of the $\mathrm{SiO}_{2}$ microspheres was not obvious, and the $\mathrm{SiO}_{2}$ microspheres exhibited a certain aging property in the dispersion. After a long time of storage, the size of the microspheres changed, which was not conducive to their self-assembly into photonic crystals. The microsphere emulsion was mixed with PA emulsion, and the PA could fill the microsphere gap in the photonic crystal structure. Then, the microsphere glue was combined to improve the wear resistance and hydrophobicity of coating. In this study, the structural color of light wood surface was more brilliant, and the iridesis effect was more obvious than in the case of dark wood. 
For the surface color of bamboo wood-based panels, Shen et al. (2012) mixed a poly(styrene-butyl acrylate-acrylic acid) (P(St-BA-AA)) soft polymer colloidal microsphere emulsion with $\mathrm{SiO}_{2}$ particles to form a nanocomposite dispersion solution. A structure color coating was formed on the surface of bamboo particleboard by the selfassembly of the polymer and $\mathrm{SiO}_{2}$ particles. Because the $\mathrm{P}(\mathrm{St}-\mathrm{BA}-\mathrm{AA})$ microsphere had a low glass transition temperature, it deformed and merged when the microsphere was assembled independently, filling the space between the spheres, and forming a transparent film. In this study, the size of the $\mathrm{SiO}_{2}$ particles was about $20 \mathrm{~nm}$, which could be filled between P(St-BA-AA) microspheres in the process of common self-assembly. Due to the difference in refractive indexes between the polymer and $\mathrm{SiO}_{2}$, the structural color was generated. Compared with glass and plastic, bamboo particleboard substrates contain more hydroxyl groups and formed hydrogen bonds with the carboxyl groups on the surface of the microspheres. Thus, the coatings on the surface exhibited higher reflectivity and adhesion. The film's self-assembly temperature was adjusted to endow reagent responsiveness. At $30{ }^{\circ} \mathrm{C}$, the self-assembled film was colorless and transparent. When water, ethanol, acetone, and other reagents were added to the surface, the film exhibited bright color (Shen et al. 2013). At the same time, the colorless film had good superhydrophobic properties (Shen et al. 2018).

In the field of new pigments for wood, Aguirre et al. (2010) prepared 3D photonic crystals by centrifugal deposition. The powder photonic crystal was mixed with nano carbon black to form a low-angle-dependent photonic crystal pigment. The pigment was coated on the surface of wood and other materials with adhesive to provide different colors to the materials. When the photonic crystals were mixed with carbon black, the multiple scattering of light was greatly reduced, and the structure color saturation was enhanced.

In addition to the application of structural color in wood materials, cellulose nanocrystals prepared from wood materials can self-assemble under certain conditions to form films with structural color. Ligneous nanofiber crystals were prepared by strong acid hydrolysis combined with high-pressure homogenization, and self-assembly induced by ultrasonic treatment to form chiral arranged photonic crystal films and produce structural colors (Revol et al. 1994; Dong et al. 1998; Isogai et al. 2011; Majoinen et al. 2012; Kelly et al. 2013b; Qing et al. 2013). Kelly et al. (2013a) mixed lignocellulose nanocrystals with acrylamide monomer, crosslinker, and 2,2-diethoxyacetophenone initiator to prepare nanocomposite hydrogels with light response through evaporation-induced self-assembly and photo-polymerization. When the mixture ratio of cellulose nanocrystals and acrylamide monomer was 1:0.52, the chiral nematic hydrogel showed a near-infrared rainbow color. When a small amount of $\mathrm{NaCl}$ was added to the mixture, the ionic strength of emulsion increased, and the reaction of the hydrogel to light wave resulted in a blue shift after self-assembly. Yao et al. (2017) prepared cellulose nanocrystalline/PEG composite films with large size and smoothness. When the ratio of the two was adjusted to 9:1, 8:2, and 7:3, three structural colors of blue, green, and red could be endowed to the film. In this study, the chiral column structure underwent reversible swelling and drying shrinkage due to the change in humidity of the external environment, leading to a change in film color and exhibiting excellent humidity sensing performance. Meanwhile, due to the addition of PEG, the composite film exhibited better mechanical strength and thermal stability.

Based on the mechanism of color generation of photonic crystal structures, a longrange ordered structure was constructed on the surface of the wood with submicron spheres as the basic structural unit. Through the self-assembly behavior of submicron spheres, the biomimetic construction of a photonic crystal structure film on the wood surface can 
modulate photons, improve the wood color, and effectively avoid the fading and pollution of dye dyeing. Cellulose nanocrystals made of wood as raw material can form a chiral array structure with circular dichroism and structural color through self-assembly.

\section{CONCLUDING REMARKS}

At present, wood biomimetics research is increasing. Through applying structural color to improvement of wood color, we can learn from nature from three aspects of surface microstructure, optical function, and color, to achieve the integration of structure and function, provide new ideas, principles, and methods for wood color improvement, expand the means of wood color improvement, and consolidate its theoretical basis, which can considerably improve the value of wood. The application field has important research significance. The research on wood structure color biomimetics will promote the cross fusion between wood science and optics, color science, nano science, and interface science. The mechanism of light response and interface combination in the field of wood optical biomimetics will be extended, and the connotation of wood science and wood biomimetics will be further explored with great scientific significance.

In conclusion, future research of wood biomimetic structure color should focus on the following four aspects. The first topic should (a) investigate the new approach of construction and mechanism of structural color film on a wood surface. The thermal, kinetic, and molecular dynamics of self-assembled colloidal microspheres should be simulated to elucidate the constructing mechanism of films with ordered photonic crystal structures. The second aspect should (b) study the light response and interface mechanism of wood surface structure color film. More varieties of colors should be presented to enrich the decorative effect of the wood surface and the interface nanostructure between structural color film and wood surface should be simulated to reveal the mechanism of interface regulation. The revelation of the mechanism will be helpful for the directional preparation of the structural color film of wood surface. The third discussion should (c) study the construction technology of large size and patterned biomimetic structure color film on wood surface that can be developed by spraying and digital inkjet printing. This technique can imitate the color, luster, and texture of precious wood, mother-of-pearl inlay, and stone. In this way, the value of low-quality wood can be improved. Lastly, the fourth aspect should elaborate on the (d) methods for the preparation of chiral structural color materials with specific colors and functions, which can be explored using lignocellulosic nanocrystals as the main raw material. This material will be used in intelligent display, intelligent windows, sensing, anticounterfeiting, stealth, among other fields.

\section{ACKNOWLEDGEMENTS}

The authors are grateful for the financial support from the National Key R \& D Program of China (Grant No. 2016YFD0600704), Youth Program of Science and Technology Innovation Fund of Nanjing Forestry University (Grant No. CX2019016) and the Priority Academic Program Development (PAPD) of Jiangsu Province, China. 


\section{REFERENCES CITED}

Aguirre, C. I., Reguera, E., and Stein, A. (2010). "Colloidal photonic crystal pigments with low angle dependence," ACS Appl. Mater. Inter. 2(11), 3257-3262. DOI: 10.1021/am100704f

Bao, M., Huang, X., Zhang, Y., Yu, W., and Yu, Y. (2016). "Effect of density on the hygroscopicity and surface characteristics of hybrid poplar compreg," J. Wood Sci. 62(5), 441-451. DOI: 10.1007/s10086-016-1573-4

Bekhta, P., and Niemz, P. (2003). "Effect of high temperature on the change in color, dimensional stability and mechanical properties of spruce wood," Holzforschung 57(5), 539-546. DOI: 10.1515/HF.2003.080

Born, M., and Wolf, E. (1999). Principles of Optics, Cambridge University Press, Cambridge, UK.

Borrega, M., Ahvenainen, P., Serimaa, R., and Gibson, L. (2015). “Composition and structure of balsa (Ochroma pyramidale) wood," Wood Sci. Technol. 49(2), 403-420. DOI: $10.1007 / \mathrm{s} 00226-015-0700-5$

Cakicier, N., Korkut, S., and Guler, F. D. (2011). "Effects of heating treatment on some of the physical properties of varnish layers applied on various wood species," Afr. J. Biotechnol. 10(9), 1578-1585. DOI: 10.5897/AJB10.1341

Chen, J., Xie, J., Wu, Z., Elbashiry, E. M. A., and Lu, Y. (2015). "Review of beetle forewing structures and their biomimetic applications in China: (I) On the structural colors and the vertical and horizontal cross-sectional structures," Mater. Sci. Eng. C 55(1), 605-619. DOI: 10.1016/j.msec.2015.05.064

Chen, M., Zhou, L., Guan, Y., and Zhang, Y. (2013). "Polymerized microgel colloidal crystals: Photonic hydrogels with tunable band gaps and fast response rates," Angew. Chem. Int. Edit. 52(38), 9961-9965. DOI: 10.1002/anie.201302466

Cheng, B., Ni, P., Jin, C., Li, Z., Zhang, D., Dong, P., and Guo, X. (1999). "More direct evidence of the fcc arrangement for artificial opal," Opt. Commun. 170(1-3), 41-46. DOI: $10.1016 / \mathrm{S} 0030-4018(99) 00434-4$

Choi, S., and Chung, H. (2013). "Novel co-matrix systems for the MALDI-MS analysis of polystyrene using a UV absorber and stabilizer," Analyst 138(4), 1256-1261. DOI: $10.1039 / \mathrm{c} 2 \mathrm{an} 35718 \mathrm{f}$

Cong, H., Yu, B., Wang, S., Qi, L., Wang, J., and Ma, Y. (2013). "Preparation of iridescent colloidal crystal coatings with variable structural colors," Opt. Express 21(15), 17831-17838. DOI: 10.1364/OE.21.017831

Deka, M., Gindl, A. W., Wimmer, R., and Christian, H. (2007). "Chemical modification of Norway spruce (Picea abies (L) Karst) wood with melamine formaldehyde resin," Indian J. Chem. Techn. 14(2), 134-138. DOI: 10.1016/j.fuproc.2006.11.007

Denkov, N. D., Velev, O. D., Kralchevsky, P. A., Ivanov, I. B., Yoshimura, H., and Nagayama, K. (1993). “Two-dimensional crystallization," Nature 361, 26. DOI: $10.1038 / 361026 \mathrm{a} 0$

Dong, X., M., Revol, J., and Gray, D., G. (1998). "Effect of microcrystallite preparation conditions on the formation of colloid crystals of cellulose," Cellulose 5, 19-32. DOI: 10.1023/A:1009260511939

Esteves, B., Marques, A. V., Domingos, I., and Pereira, H. (2008). "Heat-induced colour changes of pine (Pinus pinaster) and eucalypt (Eucalyptus globulus) wood," Wood Sci. Technol. 42, 369-384. DOI: 10.1007/s00226-007-0157-2 
Finlayson, C. E., and Baumberg, J. J. (2013). "Polymer opals as novel photonic materials," Polym. Int. 62(10), 1403-1407. DOI: 10.1002/pi.4582

Forster, J. D., Non, H., Liew, S. F., Saranathan, V., Schreck, C. F., Yang, L., Park, J. G., Prum, R. O., Mochrie, S. G. J., O'Hern, C. S., et al. (2010). "Biomimetic isotropic nanostructures for structural coloration," Adv. Mater. 22(26-27), 2939-2944. DOI: 10.1002/adma.200903693

Galusha, J. W., Richey, L. R., Gardner, J. S., Cha, J. N., and Bartl, M. H. (2008). "Discovery of a diamond-based photonic crystal structure in beetle scales," Phys. Rev. E 77(5), Article ID 050904(R). DOI: 10.1103/PhysRevE.77.050904

Gamaliel, L., Basterra, L. A., and Luis, A. (2018). "Infrared thermography for wood densitry estimation," Infrared Phys. Techn. 89, 242-246. DOI: 10.1016/j.infrared.2018.01.015

Gao, W., Rigout, M., and Owens H. (2017). "Optical properties of cotton and nylon fabrics coated with silica photonic crystals," Opt. Mater. Express. 7(2), 341. DOI: 10.1364/OME.7.000341

Ghafarzadeh, R., Shams-Nateri, A., Shojaie, A. F. (2018). "Effect of $\mathrm{TiO}_{2}$ nanoparticle on light fastness and degradation of dyed fabric with direct dye," Indian J. Fibre. Text. 43(3), 363-368. URI: http://nopr.niscair.res.in/handle/123456789/45026

Giese, M., Blusch, L. K., Khan, M. K., Hamad, W. Y., and MacLachlan, M. J. (2014). "Responsive mesoporous photonic cellulose films by supramolecular contemplating," Angew. Chem. Int. Edit. 53(34), 8880-8884. DOI: 10.1002/anie.201402214

Gogate, P. R., and Pandit, A. B. (2004). "A review of imperative technologies for wastewater treatment I: oxidation technologies at ambient conditions," Adv. Environ. Res. 8(3), 501-551. DOI: 10.1016/S1093-0191(03)00032-7

Gutierrez, S. M. V., and Robinson, S. C. (2017). "Microscopic analysis of pigments extracted from spalting fungi," J. Fungi 3(1), Article number 15. DOI: 10.3390/jof3010015

Hansmann, C., Deka, M., Wimmer, R., and Gindl, W. (2006). "Artificial weathering of wood surfaces modified by melamine formaldehyde resins," Eur. J. Wood Wood Prod. 64 (3), 198-203. DOI: 10.1007/s00107-005-0047-y

Hinsch, E. M., and Robinson, S. C. (2018). "Comparing colorfastness to light of woodstaining fungal pigments and commercial dyes: An alternative light test method for color fastness," Coatings 8(5), Article number 189. DOI: 10.3390/coatings8050189

Honda, M., Seki, T., and Takeoka, Y. (2009). "Dual tuning of the photonic band-gap structure in soft photonic crystals," Adv. Mater. 21(18), 1801-1804. DOI: 10.1002/adma.200801258

Hu, J., Li, Y., Yi, L., Guo, H., and Li, L. (2016). "Evaluation of the dyeing properties of basswood veneer treated by dichlorotriazine reactive dye based on gray correlation analysis," BioResources 11(1), 466-481. DOI: 10.15376/biores.11.1.466-481

Huang, X., Kocaefe, D., Kocaefe, Y., Boluk, Y., and Pichette, A. (2012). “A spectrocolorimetric and chemical study on color modification of heat-treated wood during artificial weathering," Appl. Surf. Sci. 258(14), 5360-5369. DOI: 10.1016/j.apsusc.2012.02.005

Inan, H., Poyraz, M., Inci, F., Lifson, M. A., Baday, M., Cunningham, B. T., and Demirci, U. (2017). "Photonic crystals: Emerging biosensors and their promise for point-of-care applications," Chem. Soc. Rev. 46(2), 366-388. DOI: $10.1039 / \mathrm{c} 6 \mathrm{cs} 00206 \mathrm{~d}$ 
Isapour, G., and Lattuada, M. (2018). "Bioinspired stimuli-responsive color-changing systems," Adv. Mater. 30(19), Article ID 1707069. DOI: 10.1002/adma.201707069

Isogai, A., Saito, T., and Fukuzumi, H. (2011). "TEMPO-oxidized cellulose nanofibers," Nanoscale 3(1), 71-85. DOI: 10.1039/C0NR00583E

Jaxel, J., Gusenbauer, C., Böhmdorfer, S., Liebner, F., and Hansmanna, C. (2020). "Improving single-step $\mathrm{scCO}_{2}$ dyeing of wood by DMSO-induced micro-swelling," $J$. Supercrit. Fluid. 165, Article number 104978. DOI: 10.1016/j.supflu.2020.104978

Jiang, P., Bertone, J. F., Hwang, K. S., and Colvin, V. L. (1999). Single-crystal colloidal multilayers of controlled thickness. Chem. Mater. 11, 2132-2140. DOI: $10.1021 / \mathrm{cm} 990080+$

Kanaya, S., Kariya, K., and Fujisaki, W. (2016). "Cross-modal correspondence among vision, audition, and touch in natural objects: An investigation of the perceptual properties of wood," Perception 45(10), 1099-1114. DOI:

10.1177/0301006616652018

Kelly, J. A., Shukaliak, A. M., Cheung, C. C. Y., Shopsowitz, K. E., Hamad, W. Y., and Maclachlan, M. J. (2013a). "Responsive photonic hydrogels based on nanocrystalline cellulose," Angew. Chem. Int. Edit. 52(34), 8912-8916. DOI:

10.1002/anie.201302687

Kelly, J. A., Yu, M., Hamad, W. Y., and MacLachlan, M. J. (2013b). "Large, crack-free freestanding films with chiral nematic structures," Adv. Opt. Mater. 1(4), 295-299. DOI: 10.1002 /adom.201300015

Kinoshita, S., and Yoshioka, S. (2005). "Structural colors in nature: The role of regularity and irregularity in the structure," ChemPhysChem 6(8), 1442-1459. DOI: 10.1002/cphc. 200500007

Knudson, R., and Brunette, G. (2015). "Evaluation of Canadian prairie-grown hybrid poplar for high value solid wood products," Forest. Chron. 91(2), 141-149. DOI: $10.5558 / \mathrm{tfc} 2015-025$

Kohri, M., Yamazaki, S., Kawamura, A., Taniguchi, T., and Kishikawa, K. (2017). "Bright structural color films independent of background prepared by the dip-coating of biomimetic melanin-like particles having polydopamine shell layers," Colloids Surf. A- Physicochem. Eng. Asp. 532, 564-569. DOI: 10.1016/j.colsurfa.2017.03.035

Kolle, M., Lethbridge, A., Kreysing, M., Baumberg, J. J., Aizenberg, J., and Vukusic, P. (2013). "Bio-inspired band-gap tunable elastic optical multilayer fibers," Adv. Mater. 25(15), 2239-2245. DOI: 10.1002/adma.201203529

Kušić, H., Božić, A. L., and Koprivanac, N. (2007). "Fenton type processes for minimization of organic content in coloured wastewaters: Part I: Processes optimization," Dyes Pigm. 74(2), 380-387. DOI: 10.1016/j.dyepig.2006.02.022

Lei, X., Yu, B., Cong, H., Tian, C., Wang, Y., Wang, Q., and Liu, C. (2014). "Synthesis of monodisperse silica microspheres by a modified Stöber method," Integr. Ferroelectr. 154(1), 142-146. DOI: 10.1080/10584587.2014.904651

Li, H. L. and Marlow, F. (2006). "Solvent effects in colloidal crystal deposition," Chem. Mater. 18(7), 1803-1810. DOI: 10.1021/cm052294z

Li, N., Chen, Y., Bao, Y., Zhang, Z., Wu, Z., and Chen, Z. (2015). "Evaluation of UVpermeability and photo-oxidisability of organic ultraviolet radiation-absorbing coatings," Appl. Surf. Sci. 332, 186-191. DOI: 10.1016/j.apsusc.2015.01.112 
Li, Q., Zhang, Y., Shi, L., Qiu, H., Zhang, S., Qi, N., Hu, J., Yuan, W., Zhang, X., and Zhang, K. (2018). "Additive mixing and conformal coating of noniridescent structural colors with robust mechanical properties fabricated by atomization deposition," ACS Nano 12(4), 3095-3102. DOI: 10.1021/acsnano.7b08259

Li, X. J., Cai, Z. Y., Mou, Q. Y., Wu, Y. Q., and Liu, Y. (2011). "Effects of heat treatment on some physical properties of Douglas fir (Pseudotsuga Menziesii) wood," Adv. Mater. Res. 197, 90-95. DOI: 10.4028/www.scientific.net/AMR.197-198.90

Liu, G., Zhou, L., Wu, Y., Wang, C., Fan, Q., Shao, J. (2015). “The fabrication of full color P(St-MAA) photonic crystal structure on polyester fabrics by vertical deposition self-assembly," J. Appl. Polym. Sci. 132(13). DOI: 10.1002/app.41750

Liu, G., Zhou, L., Zhang, G., Li, Y., Chai, L., Fan, Q., and Shao, J. (2016). "Fabrication of patterned photonic crystals with brilliant structural colors on fabric substrates using ink-jet printing technology," Mater. Design. 114(15), 10-17. DOI: 10.1016/j.matdes.2016.09.102

Liu, G., Zhou, L., Zhang, G., Li, Y., Chai, L., Fan, Q., and Shao, J. (2017). "Fabrication of patterned photonic crystals with brilliant structural colors on fabric substrates using ink-jet printing technology," Mater. Design 114, 10-17. DOI: 10.1016/j.matdes.2016.09.102

Liu, H., Zhang, J., Jiang, W., and Cai, Y. (2019). "Characteristics of commercial-scale radio-frequency/ vacuum (RF/V) drying for hardwood lumber," BioResources 14(3), 6923-6935. DOI: 10.15376/biores.14.3.6923-6935

Liu, Y., Hu, J., and Wu, Z. (2020a). "Fabrication of coatings with structural color on a wood surface," Coatings 10(1), Article number 32. DOI: 10.3390/coatings10010032

Liu, Y., Shao, L., Gao, J., Guo, H., Chen, Y., Chen, Q., and Via, B. K. (2015). "Surface photo-discoloration and degradation of dyed wood veneer exposed to different wavelengths of artificial light," Appl. Surf. Sci. 331, 353-361. DOI: 10.1016/j.apsusc.2015.01.091

Liu, Y., Yu, Z., Zhang, Y., Qi, C., Tang, R., Zhao, B., Wang, H., and Han, Y. (2020b). "Microbial dyeing-infection behavior and influence of Lasiodiplodia theobromae in poplar veneer," Dyes Pigm. 173, Article ID 107988. DOI:

10.1016/j.dyepig.2019.107988

Liu, Z., Chen, S., and Zhang, J. (2013). "Effect of UV absorbers and hindered amine light stabilizers on the photodegradation of ethylene-octene copolymer," J. Appl. Polym. Sci. 127(2), 1135-1147. DOI: 10.1002/app.37955

Lopez-Garcia, M., Masters, N., O'Brien, H. E., Lennon, J., Atkinson, G., Cryan, M. J., Oulton, R., and Whitney, H. M. (2018). "Light-induced dynamic structural color by intracellular 3D photonic crystals in brown algae," Sci. Adv. 4(4), Article ID eaan8917. DOI: $10.1126 /$ sciadv.aan8917

Luo, W., Yan, J., Tan, Y., Ma, H., and Guan, J. (2017). "Rotating 1-D magnetic photonic crystal balls with tunable lattice constant," Nanoscale 9(27), 9548-9555. DOI: 10.1039/C7NR03335D

Majoinen, J., Kontturi, E., Ikkala, O., and Gray, D. (2012). "SEM imaging of chiral nematic films cast from cellulose nanocrystal suspensions," Cellulose 19(5), 15991605. DOI: $10.1007 / \mathrm{s} 10570-012-9733-1$

Mamnicka, J., and Czajkowski, W. (2012). "New fiber-reactive UV-absorbers increasing protective properties of cellulose fibres," Cellulose 19(5), 1781-1790. DOI: $10.1007 / \mathrm{s} 10570-012-9753-\mathrm{x}$ 
McGrath, J. G., Bock, R. D., Cathcart, J. M., and Lyon L. A. (2007). "Self-assembly of "Paint-On" colloidal crystals using poly(styrene-co-N-isopropylacrylamide) spheres," Chem. Mater. 19, 1584-1591. DOI: 10.1021/cm061931y

Mesnage, A., Lefèvre, X., Pascale, J., Deniau, G., and Palacin, S. (2012). "Spontaneous grafting of diazonium salts: Chemical mechanism on metallic surfaces," Langmuir 28(32), 11767-11778. DOI: 10.1021/la3011103

Míguez, H., Meseguer, F., López, C., Mifsud, A., Moya, J. S., and Vázquez, L. (2007). "Evidence of FCC crystallization of $\mathrm{SiO}_{2}$ nanospheres," Langmuir 13(23), 60096011. DOI: 10.1021/la970589o

Moon, J. H., Yi, G. R., and Yang, S. M. (2005). "Fabrication of hollow colloidal crystal cylinders and their inverted polymeric replicas," J. Colloid Interf. Sci. 287(1), 173177. DOI: 10.1016/j.jcis.2005.01.067

Nassau, K. (2001). The Physics and Chemistry of Color, John Wiley \& Sons Inc., New York, NY, USA.

Núñez-Montenegro, A., Crista, D. M. A., and Esteves Da Silva, J. C. G. (2020). "Structural coloration based on photonic crystals for coating applications on wood," Eur. J. Wood Wood Prod. 78(2), 293-300. DOI: 10.1007/s00107-020-01499-9

Park, T. J., Hwang, S. K., Park, S., Cho, S. H., Park, T. H., Jeong, B., Kang, H. S., Ryu, D. Y., Huh, J., Thomas, E. L., et al. (2015). "Electrically tunable soft-solid block copolymer structural color," ACS Nano 9(12), 12158-12167. DOI:

10.1021/acsnano.5b05234

Prum, R. O., Cole, J. A., and Torres, R. H. (2004). "Blue integumentary structural colours in dragonflies (Odonata) are not produced by incoherent tyndall scattering," J. Exp. Biol. 207(22), 3999-4009. DOI: 10.1242/jeb.01240

Prum, R. O., Dufresne, E. R., Quinn, T., and Waters, K. (2009). "Development of colourproducing $\beta$-keratin nanostructures in avian feather barbs," J. R. Soc. Interface 6(Suppl_2), S253-S265. DOI: 10.1098/rsif.2008.0466.focus

Pusey, P. N., Van Megen, W., Bartlett, P., Ackerson, B. J., Rarity, J. G., and Underwood, S. M. (1989). "Structure of crystals of hard colloidal spheres," Phys. Rev. Lett. 63(25), 2753-2756. DOI: 10.1103/PhysRevLett.63.2753

Qing, Y., Sabo, R., Zhu, J. Y., Agarwal, U., Cai, Z., and Wu, Y. (2013). "A comparative study of cellulose nanofibrils disintegrated via multiple processing approaches," Carbohyd. Polym. 97(1), 226-234. DOI: 10.1016/j.carbpol.2013.04.086

Rajan, V. V., Wäber, R., and Wieser, J. (2012). "Influence of different types of UV absorber/UV stabilizer combination on the photodegradation of PC/ABS blend," $J$. Appl. Polym. Sci. 124(5), 4007-4015. DOI: 10.1002/app.34560

Revol, J., Godbout, L., Dong, X., Gray, D., G., Chanzy, H., and Maret, G. (1994). “Chiral nematic suspensions of cellulose crystallites; phase separation and magnetic field orientation," Liq. Cryst. 16(1), 127-134. DOI: 10.1080/02678299408036525

Robinson, S. C., Hinsch, E., Weber, G., Leipus, K., and Cerney, D. (2014). "Wood colorization through pressure treating: The potential of extracted colorants from spalting fungi as a replacement for woodworkers' aniline dyes," Materials 7(8), 54275437. DOI: $10.3390 / \mathrm{ma} 7085427$

Robinson, S. C., Laks, P. E., Richter, D. L., and Pickens, J. B. (2007). "Evaluating loss of machinability in spalted sugar maple," Forest Prod. J. 57(4), 33-37.

Rogach, A. L., Kotov, N. A., Koktysh, D. S., Ostrander, J. W., and Ragoisha, G. A. (2000). "Electrophoretic deposition of latex-based 3D colloidal photonic crystals: A 
technique for rapid production of high-quality opals," Chem. Mater. 2000, 12, 27212726. DOI: $10.1021 / \mathrm{cm} 0002741$

Salca, E. A., Kobori, H., Inagaki, T., Kojima, Y., and Suzuki S. (2016). "Effect of heat treatment on colour changes of black alder and beech veneers," J. Wood. Sci. 62, 297304. DOI: 10.1007/s10086-016-1558-3

Saranathan, V., Osuji, C., Mochrie, S., Noh, H., and Narayanan, S. (2010). "Crystals in butterfly wing scales," Proc. Natl. Acad. Sci. USA 107(26), 11676-11681. DOI: 10.1073/pnas.0909616107

Schmidt, A., Bach, E., and Schollmeyer, E. (2003). "The dyeing of natural fibres with reactive disperse dyes in supercritical carbon dioxide," Dyes Pigm. 56(1), 27-35. DOI: 10.1016/S0143-7208(02)00108-0

Schubert, E. F., Kim, J. K., and Xi, J. Q. (2007). "Low-refractive-index materials: A new class of optical thin-film materials," Phys. Status Solidi B - Basic Solid State Phys. 244(8), 3002-3008. DOI: 10.1002/pssb.200675603

Shen, Y., Wu, Y., Shen, Z., and Chen, H. (2018). "Fabrication of self-healing superhydrophobic surfaces from water-soluble polymer suspensions free of inorganic particles through polymer thermal reconstruction," Coatings 8(4), Article number 144. DOI: $10.3390 /$ coatings 8040144

Shen, Z., Yang, Y., Lu, F., Bao, B., and You, B. (2012). "Self-assembly of binary particles and application as structural colors," Polym. Chem. 3(9), 2495-2501. DOI: 10.1039/C2PY20305G

Shen, Z., Yang, Y., Lu, F., Bao, B., You, B., and Shi, L. (2013). "Self-assembly of colloidal spheres and application as solvent responding polymer film," J. Colloid Interface Sci. 389(1), 77-84. DOI: 10.1016/j.jcis.2012.08.063

Stöber, W., Fink, A., and Bohn, E. (1968). "Controlled growth of monodisperse silica spheres in the micron size range," J. Colloid Interface Sci. 26(1), 62-69. DOI: 10.1016/0021-9797(68)90272-5

Strobel, K., Nyrud, A. Q., and Bysheim, K. (2017). "Interior wood use: linking user perceptions to physical properties," Scand. J. Forest Res. 32(8), 798-806. DOI: 10.1080/02827581.2017.1287299

Sun, M., and Song, K. (2018). "Low temperature hydrothermal fabrication of tungsten trioxide on the surface of wood with photochromic and superhydrophobic properties," BioResources 13(1), 1075-1087. DOI: 10.15376/biores.13.1.1075-1087

Sundqvist, B., Karlsson, O., and Westermark, U. (2006). "Determination of formic-acid and acetic acid concentrations formed during hydrothermal treatment of birch wood and its relation to colour, strength and hardness," Wood Sci. Technol. 40, Article number 549. DOI: 10.1007/s00226-006-0071-z

Takeoka, Y. (2012). "Angle-independent structural coloured amorphous arrays," $J$. Mater. Chem. C 22(44), 23299-23309. DOI: 10.1039/C2JM33643J

Takeoka, Y. (2013). "Stimuli-responsive opals: Colloidal crystals and colloidal amorphous arrays for use in functional structurally colored materials," J. Mater. Chem. C 1(38), 6059-6074. DOI: 10.1039/C3TC30885E

Takeoka, Y. (2017). "Angle-independent colored materials based on the Christiansen effect using phase-separated polymer membranes," Polym. J. 49(3), 301-308. DOI: 10.1038/pj.2016.117

Takeoka, Y., Yoshioka, S., Takano, A., Arai, S., Nueangnoraj, K., Nishihara, H., Teshima, M., Ohtsuka, Y., and Seki, T. (2013). "Production of colored pigments with 
amorphous arrays of black and white colloidal particles," Angew. Chem. Int. Edit. 52(28), 7261-7265. DOI: 10.1002/anie.201301321

Tang, B., Zheng, X., Lin, T., and Zhang, S. (2014). "Hydrophobic structural color films with bright color and tunable stop-bands," Dyes Pigm. 104, 146-150. DOI: 10.1016/j.dyepig.2014.01.008

Trau, M., Saville, D. A., and Aksay, I. A. (1996). "Field-induced layering of colloidal crystals," Science 272, 706-709. DOI: 10.1126/science.272.5262.706

Vakhittova, N. A., and Safonov, V. (2003). "Effect of chitosan on the efficiency of dyeing textiles with active dyes," Fibre Chem. 35, 27-28. DOI: 10.1023/A:1023819521538

Visschers, M., Laven, J., and van der Linde R. (1997). "Forces operative during film formation from latex dispersions," Prog. Org. Coat. 31(4), 311-323. DOI: 10.1016/S0300-9440(97)00089-1

Wang, J., Wen, Y., Ge, H., Sun, Z., Zheng, Y., Song, Y., and Jiang, L. (2006). “Simple fabrication of full color colloidal crystal films with tough mechanical strength," Macromol. Chem. Phys. 207(6), 596-604. DOI: 10.1002/macp.200500563

Wang, X., Shen, Z., Sang, T., Cheng, X., Li, M., Chen, L., and Wang, Z. (2010). "Preparation of spherical silica particles by Stöber process with high concentration of tetra-ethyl-orthosilicate,” J. Colloid Interface Sci. 341(1), 23-29. DOI: 10.1016/j.jcis.2009.09.018

Wang, X., Tang, R., Zhang, Y., Yu, Z., and Qi, C. (2016). "Preparation of a novel chitosan based biopolymer dye and application in wood dyeing," Polymers 8(9), Article number 338. DOI: 10.3390/polym8090338

Wang, X., Yu, Z., Zhang, Y., Qi, C., and Chang, W. (2018). "Evaluation of ultrasonicassisted dyeing properties of fast-growing poplar wood treated by reactive dye based on grey system theory analysis," J. Wood Sci. 64(6), 861-871. DOI: 10.1007/s10086018-1768-y

Wang, Y., Liu, C., Zhao, R., McCord, J., Rials, T., and Wang, S. (2016). “Anatomical characteristics, microfibril angle and micromechanical properties of cottonwood (Populus deltoides) and its hybrids," Biomass Bioenerg. 93, 72-77. DOI: 10.1016/j.biombioe.2016.06.011

Wang, Z., Zhang, J., Xie, J., Wang, Z., Yin, Y., Li, J., Li, Y., Liang, S., Zhang, L., and Cui, L. (2012). "Polymer Bragg stack as color tunable photonic paper," J. Mater. Chem. 22(16), 7887-7893. DOI: 10.1039/C2JM15943K

Wilts, B. D., and Saranathan, V. (2018). "A literal elytral rainbow: Tunable structural colors using single diamond biophotonic crystals in Pachyrrhynchus congestus weevils," Small 14(46), Article ID 1802328. DOI: 10.1002/smll.201802328

Xiao, Z., Xie, Y., Adamopoulos, S., and Mai, C. (2012). "Effects of chemical modification with glutaraldehyde on the weathering performance of Scots pine sapwood," Wood Sci. Technol. 46(4), 749-767. DOI: 10.1007/s00226-011-0441-z

Xuan, R., and Ge, J. (2012). "Invisible photonic prints shown by water," J. Mater. Chem. 22(2), 367-372. DOI: 10.1039/C1JM14082E

Yang, G. C., Zhou, Z. X., Cai, J. R., Zhang, Q. H. (2020). “Analysis of fading mechanism of salix integra dyed with reactive dye under ultraviolet irradiation by tri-step infrared spectroscopy," J. Mol. Struct. 1217, Article ID 128485. DOI:

10.1016/j.molstruc.2020.128485 
Yang, L., Liu, H., Cai, Y., and Wu, Z. (2019). "A novel method of studying the collapsed cell of eucalyptus wood using X-ray CT scanning," Dry. Technol. 37(12), 1597-1604. DOI: $10.1080 / 07373937.2018 .1519572$

Yao, K., Meng, Q., Bulone, V., and Zhou Q. (2017). "Flexible and responsive chiral nematic cellulose nanocrystal/poly(ethylene glycol) composite films with uniform and tunable structural color," Adv. Mater. 29(28), Article ID 1701323. DOI: 10.1002/adma.201701323

Yin, H., Dong, B., Liu, X., Zhan, T., Shi, L., Zi, J., and Yablonovitch, E. (2012). "Amorphous diamond-structured photonic crystal in the feather barbs of the scarlet macaw," P. Natl. A. Sci. USA 109(27), 10798-10801. DOI: 10.1073/pnas

You, S. J., Tseng, D. H., and Deng J. Y. (2008). "Using combined membrane processes for textile dyeing wastewater reclamation," Desalination 234(1-3), 426-432. DOI: 10.1016/j.desal.2007.09.113

Yuan, X., Xu, W., Huang, F., Chen, D., and Wei, Q. (2017). "Structural colour of polyester fabric coated with $\mathrm{Ag} / \mathrm{TiO}_{2}$ multilayer films," Surf. Eng. 33(3), 231-236. DOI: $10.1080 / 02670844.2016 .1216264$

Zeng, Q., Ding, C., Li, Q., Yuan, W., Peng, Y., Hu, J., and Zhang, K. (2017). "Rapid fabrication of robust, washable, self-healing superhydrophobic fabrics with noniridescent structural color by facile spray coating," $R S C A d v$. 7(14), 8443-8452. DOI: 10.1039/C6RA26526J

Zhang, H., Duan, R., Li, F., Tang, Q., and Li, W. (2007). "Microscopy evidence of the face-centered cubic arrangement of monodisperse polystyrene nanospheres," Mater. Design 28(3), 1045-1049. DOI: 10.1016/j.matdes.2005.09.024

Zhang, J., Chen, Z., Wang, Z., Zhang, W., and Ming, N. (2003). "Preparation of monodisperse polystyrene spheres in aqueous alcohol system," Mater. Lett. 57(28), 4466-4470. DOI: 10.1016/S0167-577X(03)00344-6

Zhao, B., Tian, C., Zhang, Y., Tang, T., and Wang, F. (2011). "Size control of monodisperse nonporous silica particles by seed particle growth," Particuology 9(3), 314-317. DOI: 10.1016/j.partic.2010.07.028

Zhou, N., Zhang, A., Shi, L., and Zhang, K. (2013). "Fabrication of structurally-colored fibers with axial core-shell structure via electrophoretic deposition and their optical properties," ACS Macro Lett. 2(2), 116-120. DOI: 10.1021/mz300517n

Zhu, T., Liu, S., Ren, K., Chen, J., Lin, J., and Li, J. (2018). "Colorability of dyed wood veneer using natural dye extracted from Dalbergia cochinchinensis with different organic solvents," BioResources 13(4), 7197-7211. DOI: 10.15376/biores.13.4.71977211

Zhu, X., Liu, Y., Dong, N., and Li, Z. (2017). "Fabrication and characterization of reversible thermochromic wood veneers," Sci. Rep. 7(1), Article number 16933. DOI: 10.1038/s41598-017-17238-9

Zhu, X., Liu, Y., Li, Z., and Wang, W. (2018). “Thermochromic microcapsules with highly transparent shells obtained through in-situ polymerization of urea formaldehyde around thermochromic cores for smart wood coatings," Sci. Rep. 8(1), Article number 4015. DOI: 10.1038/s41598-018-22445-Z 
Zi, J., Yu, X., Li, Y., Hu, X., Xu, C., Wang, X., Liu, X., and Fu, R. (2003). "Coloration strategies in peacock feathers," P. Natl. A. Sci. USA 100(22), 12576-12578. DOI: 10.1073/pnas.2133313100

Article submitted: July 6, 2020; Peer review completed: July 31, 2020; Revised version received and accepted: September 23, 2020; Published: October 20, 2020.

DOI: 10.15376/biores.15.4.Hu 